\title{
The Severity of Impacts During Low-Speed Water Skier Falls
}

\author{
John C. Lyons ${ }^{1}$, Mark Pollard ${ }^{2}$, Gens Goodman $^{3}$ and Timothy E. Cooney ${ }^{*}{ }^{1}$ \\ ${ }^{1}$ UPMC Hamot, Erie, PA, USA \\ ${ }^{2}$ Cooper Bone and Joint Institute, Camden, NJ, USA \\ ${ }^{3}$ William Beaumont Army Medical Center/Texas Tech University Health Sciences Center, USA
}

\begin{abstract}
Background: Little kinematic or kinetic information is available to understand risks associated with water skier falls. The present study assessed accelerations during low-speed falls and then contrasted these data against information obtained from automotive crash tests to better delineate risk of injury. The goal was to establish baseline impact information for low-speed falls during water skiing.

Methods: Twenty-seven experienced skiers were asked to deliberately make replicate forward falls at 20 miles per hour. A three-axis, electronic, waterproof accelerometer monitored either the torso or head during these maneuvers and recorded the magnitude of impacts in multiples of the force of gravity (e.g., 'g's'). Both anatomical sites were assessed for each participant. Data were averaged for the replicate runs. Using these averages, grand means were calculated for accelerations encountered along each of the three orthogonal axes measured. As well, 95\% confidence intervals of these grand means were calculated. Peak accelerations were identified for each of the three orthogonal axes measured and plotted against time to estimate durations of acceleration events (impulse).

Results: Grand means for torso accelerations ranged from 2.7 g's (95\% CI: 1.6-3.9) to 3.6 g's (95\%CI: 2.5-4.6). Grand means for head accelerations ranged from $2.5 \mathrm{~g}$ (95\%CI: $1.6-3.4)$ to $2.6 \mathrm{~g}$ (95\%CI: $1.4-3.8)$. Peak accelerations did not exceed $44 \mathrm{~g}$ 's for any participant. The average duration of these accelerations was approximately 110 milliseconds.

Conclusions: The average magnitude of accelerations during low-speed water skier falls approximates 2-4g's for either the head or torso. Based on a recent report of a 50-g threshold for brain injury, these impacts pose little risk of serious injury.
\end{abstract}

Keywords: Biomechanics, water impacts, accelerations, fall.

\section{INTRODUCTION}

Over 12 million water craft were registered throughout the United States in 2010 [1]. This popularity in watercraft use, has seen a parallel in the water ski-related injuries. A recent epidemiologic study cited an estimated 23,460 water skiing- and 4810 wakeboarding-related injuries treated in US emergency departments between 2001 and 2003 [2]. Within this same time frame, so-called skier mishaps represented the fourth-most common source of accident in 2010 as ranked by the US Coast Guard [1]. Broadly, injury etiology consisted of ski line entanglement, collision with fixed objects, propeller injuries, and falls. Falls have long been associated with intrarectal and vaginal laceration, described as rapid pressurization of an orfice [3-6] Foot, hip, and knee fracture and/or dislocations have been reported $[7,8]$, as well as tendon ruptures [9-12]. Spondylodystrophy or vertebral body wedging has been reported in competitive jumping, especially those who started skiing before skeletal maturity [13]. Of graver consequence, two case reports have documented significant internal injuries, dissection of cerebral [14] or coronary [15] vessels. Vascular injury can be induced by rapid decelerations as typified by the case report

*Address correspondence to this author at the Orthopedic Research, UPMC Hamot, 201 State Street, Erie, Pennsylvania 16550, USA; Tel: 814-8772684; Fax: 814-877-5089; E-mail: cooneyte@upmc.edu of a renal artery pseudoaneurysm three years after a deceleration injury [16]. Despite the potential for injury, we are unaware of any deceleration thresholds that have been established for water-based impacts. Roberts and Roberts (1996) cited estimates of between 5 and $9 \mathrm{~g}$ accelerations during routine, competitive water skiing maneuvers [17]. By contrast, the aerospace and automotive industries have made significant strides in measuring decelerations during an impact and then promulgating thresholds for injury. These fields have posited human tolerance to injury that spans extremely brief bouts of very high acceleration (in excess of $100 \mathrm{~g}$ ) to more sustained levels, on the order of $10 \mathrm{~g}$ [18] to $35 \mathrm{~g}[19,20]$. To our knowledge, no data are available for water impacts arising from water skiing.

Given that little or no kinematic or kinetic data are available to characterize the severity of water skier falls, we sought to quantify accelerations experienced by the head and torso during low-speed impacts. These data were then contrasted to established information derived from automotive crash testing to discern the potential for injury during a low-speed water skier fall. We hypothesized that accelerations derived from low-speed water impacts would be relatively low in magnitude, consistent with the absence of injury reporting seen in this sport. 


\section{MATERIALS AND METHODOLOGY}

Twenty-seven experienced water skiers volunteered who signed informed consent. Experienced skiers were utilized to minimize inadvertent falls, reducing both the risk associated with this study as well as eliminating spurious events. Skiers included 18 males and nine females, ages 23-49 (average: 26 \pm 5.3 years) ranging in bodyweight from 47.7 to $100 \mathrm{~kg}$. (average: $79.5 \pm 19.1 \mathrm{kgs}$ ). All were screened by the senior author for preexisting medical morbidities that would have posed a risk to their safety. This study conformed to the principles established by the Declaration of Helsinki and was approved by the hospital Institutional Review Board.

Trials consisted of six, contrived, forward falls at a speed of 20 mile per hour (32 kilometers per hour or 17.5 knots). Skiers were pulled by either a Sea Doo three-person jet ski (Bombardier Recreational Products, Sturtevant, WI) $(\mathrm{n}=3)$ or a 28 -foot Sea Ray Sundancer sport cruiser (Sea Ray, Knoxville, TN) ( $\mathrm{n}=24)$. Vessel speed was verified by onboard instrumentation. Skiers were equipped with $185-\mathrm{cm}$ water skis (OBrien, Redmond, WA), a standard adult ski jacket (Bart's Water Sports, North Webster, IN) and an adult ProTec water sport helmet (Bart's Water Sports, North Webster, IN). Skiers were instructed to release the ski rope when ready and fall forward once speed was attained. An onboard spotter provided input to the pilot about the welfare of the skier and documented the clock time of each event (fall). These times were used to abstract acceleration data at the moment of impact. Skier rotation permitted rest after the acquisition of one set (three replicates) of falls to minimize fatigue and foster skier safety.

The magnitude of impacts was measured by a waterproof, electronic, three-axis accelerometer (SnapShock Plus, Instrumented Sensor Technology, Okemos, MI). The device records data at a rate of $1200 \mathrm{hz}$ with an accuracy of $\pm 1 \%$ and was self-contained, using a rechargeable lithiumion battery for operation. Triggering was programmable so that spurious recordings could be minimized or eliminated. Once a trigger threshold was reached, the 'event' was recorded as a time-stamped entry. For three of the falls, torso accelerations were monitored using a vest pouch affixed to the ski jacket (Fig. 1a). For the other half of the trials, head accelerations were monitored by attaching the device to the helmet (Fig. 1b). In either case, the device was rigidly affixed to the piece of safety equipment. The order of monitoring was varied for each session to obviate effects of a learning curve for performing the falls. The head and torso were selected as target areas for monitoring accelerations given they house critical organs that would be susceptible to deceleration injury.

Data were downloaded from the accelerometer and summarized via descriptive statistical measures. Downloads or changes in accelerometer operating parameters were accomplished via an infrared wand connected to an IBM ThinkPad 760EL PC (IBM, Morrisville, NC). Raw data were imported into DynaMax ${ }^{\mathrm{TM}}$ Suite v1.5.3 (Instrumented Sensor Technology, Okemos, MI), a software package that allowed graphic analysis of the data as well as its tabulation. Event times were cross-referenced to documented clock times to distinguish falls from spurious triggering. The data from these falls were then imported into Microsoft Excel 2002 to generate summary data. Averages and standard deviations were calculated for each set of triplicate runs per monitored site. Grand means (means of the average values obtained for each subject) and 95\% confidence intervals were then generated as a summary measures for each orthogonal axis and anatomical area monitored. Given that duration of acceleration is used in estimating Head injury Criteria [21], the largest peak accelerations and their duration were plotted for head accelerations. Since we were unaware of any prior publication of decelerations associated with water impacts, a power analysis was not performed. Rather, we recruited a sufficient number of subjects to reduce the overall coefficient of variation to less than $25 \%$.

(a) Torso

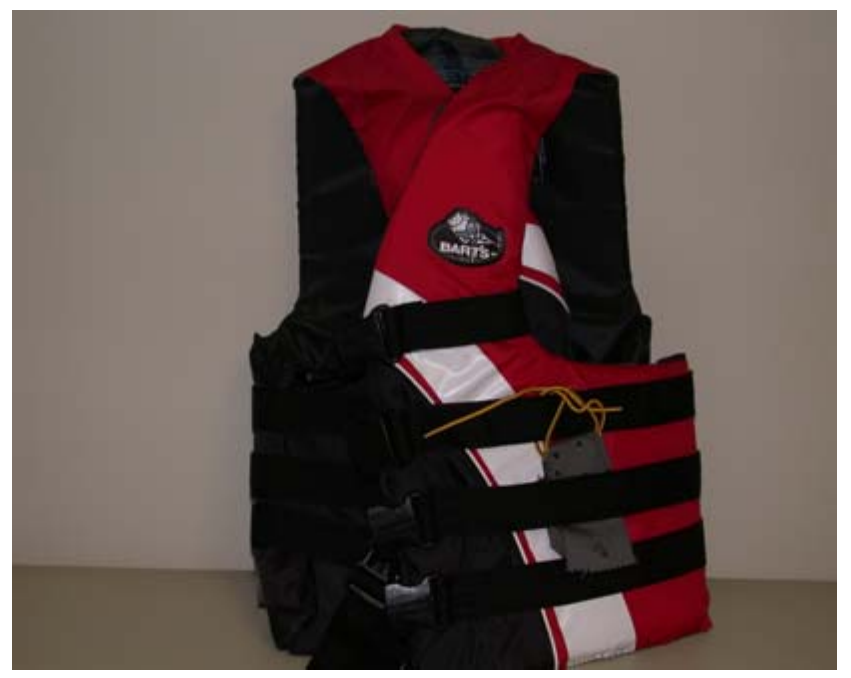

(b) Posterior Head

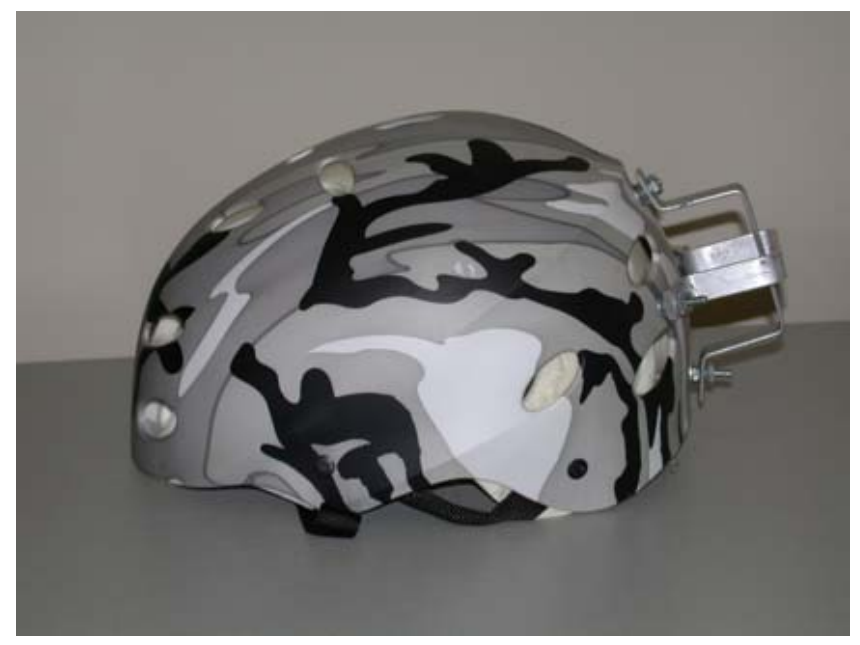

Fig. (1). (a) skier vest with accelerometer 'pocket' located on left anterolateral aspect of the torso, (b) Skier helmet with accelerometer mounting frame on the posterior aspect.

\section{RESULTS}

Means for torso accelerations for volunteer skiers (Fig. 2) ranged from $-7.5 \mathrm{~g}$ to $+10.8 \mathrm{~g}$ in the anteroposterior direction, $-3.6 \mathrm{~g}$ to $+13.4 \mathrm{~g}$ in the craniocaudal direction, and $-2.2 \mathrm{~g}$ to $+27.7 \mathrm{~g}$ in the lateral direction. Discounting directionality, absolute means were 2.7 g's (95\% CI: 1.6- 
3.9), 3.0 g's (95\%CI: 1.9-4.1), and 3.6 g's (95\%CI: $2.5-4.6)$ with peak accelerations of 33,42 , and 44 g's, respectively.

Means for head accelerations (Fig. 3) ranged from $-6.3 \mathrm{~g}$ to $+7.8 \mathrm{~g}$ in the anteroposterior direction, $-6.5 \mathrm{~g}$ to $+5.7 \mathrm{~g}$ in the craniocaudal direction, and $-2.0 \mathrm{~g}$ to $10.2 \mathrm{~g}$ in the anteroposterior direction. Absolute mean values were $2.5 \mathrm{~g}$ (95\%CI: 1.6-3.4), $2.4 \mathrm{~g} \mathrm{(95 \%} \mathrm{CI:} 1.8-3.1)$ and $2.6 \mathrm{~g}(95 \% \mathrm{CI}$ : 1.4-3.8) with peaks of 29,14 , and $31 \mathrm{~g}$, respectively.

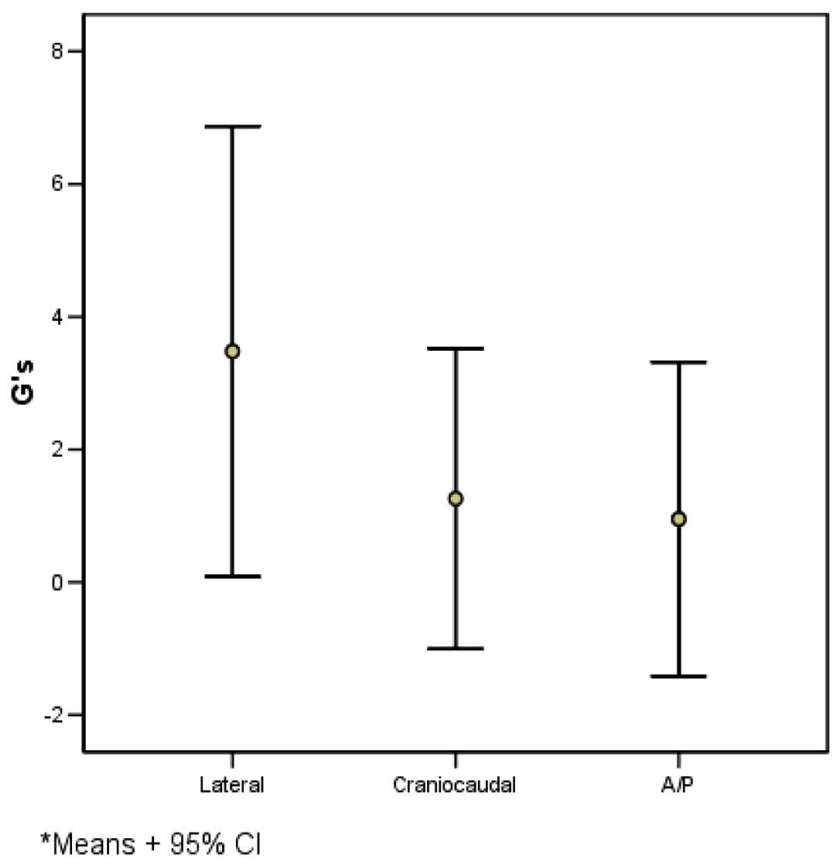

Fig. (2). Graph of average torso accelerations by axis, skier. Data represent averages of three, forward falls initiated at.

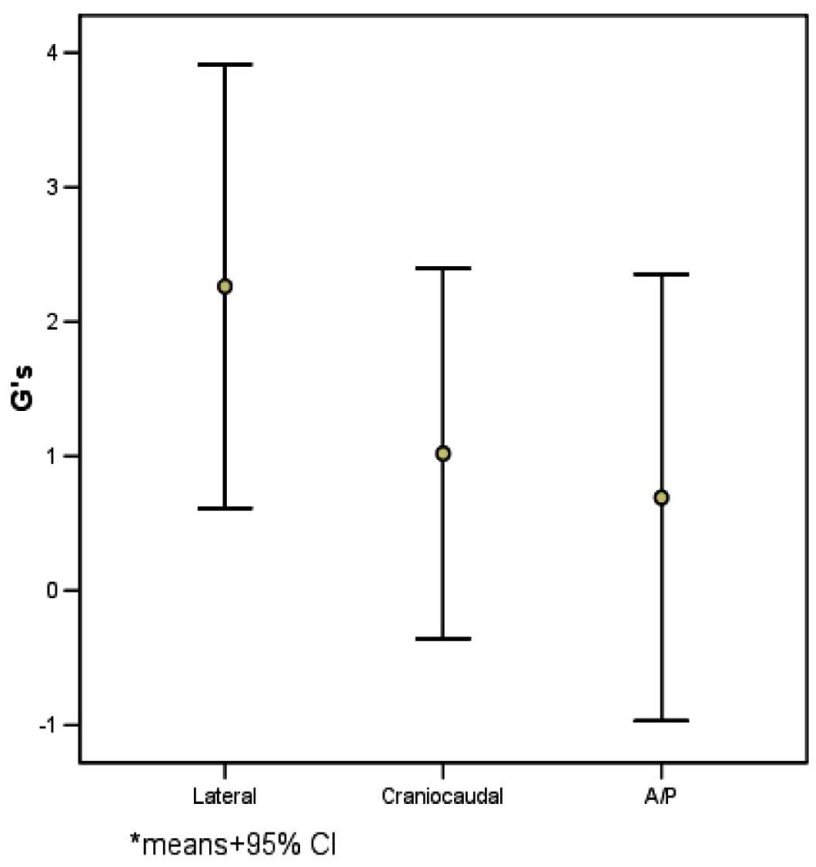

Fig. (3). Graph of average head accelerations by axis, skier.
Duration of peak accelerations was generally less than 0.1 seconds (Fig. 4). Several outliers are apparent $(\geq 1.0 \mathrm{~s})$; their occurrence conceivably may represent a skier who falls and is towed for a short period prior to rope release. Overall, skiers tolerated the falls well and no mishaps occurred.

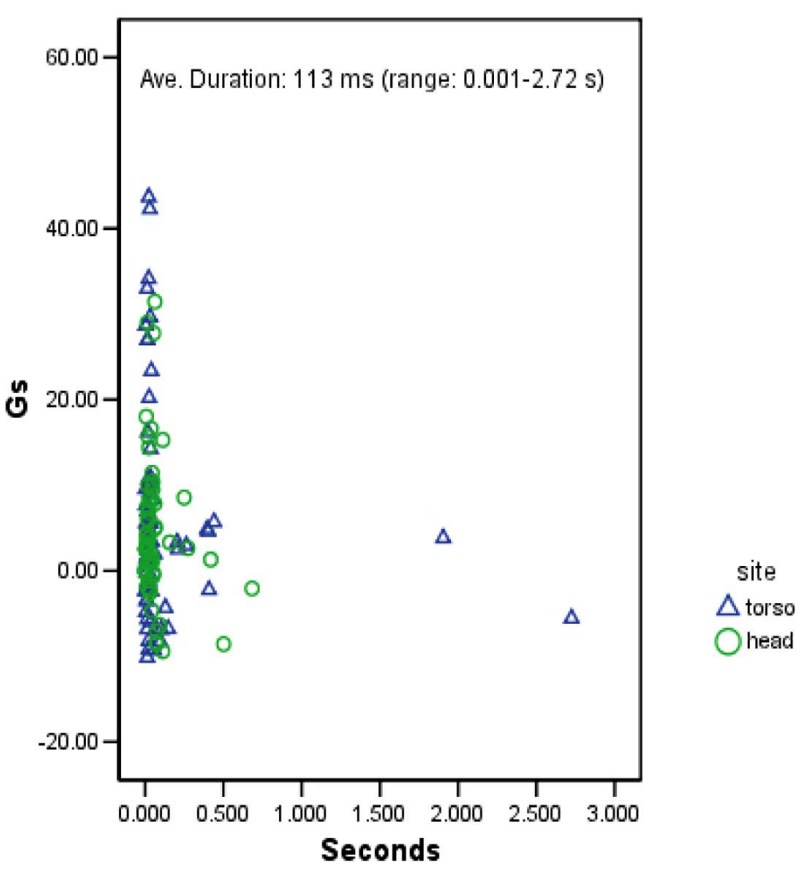

Fig. (4). Scatter plot of peak accelerations by duration.

\section{DISCUSSION}

Our data indicate that contrived, forward falls at 20 miles per hour produced impacts averaging between 2 and $4 \mathrm{~g}$ 's with highly transient peaks of up to $44 \mathrm{~g}$ 's. Despite attempts to standardize falls, data were highly variable.

These results appear to be supported by or, at the very least, consistent with other human impact studies. Literature pertinent to water impacts is limited. Zillmer (2003) failed to observe neurologic impairment following repetition dives by 3-meter springboard divers [22]. Roberts and Roberts (1996) cited estimates of between 5 and $9 \mathrm{~g}$ accelerations during routine, competitive water skiing maneuvers [17].

By contrast, there is a wealth of data obtained from automotive impacts that have established human tolerance to accelerations. Early studies simulating automotive crashes with human volunteers demonstrated tolerances to lateral accelerations of up to $10 \mathrm{~g}$ [18], frontal or rear impacts of 11-14 g [23], and test sled decelerations up to $35 \mathrm{~g}[19,20]$. At some of the higher levels of decelerations, only transient discomfort or headaches in test subjects were observed without permanent, untoward consequences. Hirsh (1968), however, noted that duration of the acceleration is also an important aspect, especially as it relates to the injury potential, citing examples of minor injury in the face of accelerations exceeding $100 \mathrm{~g}$ [24]. When contrasted against these automotive impacts, even the largest peak acceleration recorded in this study, $44 \mathrm{~g}$ 's, was less than half that cited by Hirsh. In a study of Indy car crashes, Weaver et al. (2006) suggested a "mean maximal" $G$ threshold of 50 as 
potentiating ten-times greater frequency of head injury [25]. These comparisons suggest that, consistent with our hypothesis, low-speed impacts on water result have little potential for inducing injury.

More recently, changes in human research ethics coupled with interest in tissue response to impact have prompted the use of human surrogates in impact tests. Intervertebral foramen narrowing and cervical vertebral compression and shearing have been observed in cadaver vertebrae around 3.5 g's [26,27]. Others have shown aberrant motion of the first thoracic vertebra with rear impacts of between 5 and 8 g's $[28,29]$. While these recent studies provide glimpses of anatomical/structural changes, they fail to provide relevant injury information. Of greater relevance, hepatic injury was accompanied by cadaver torso decelerations of $60 \mathrm{~g}$ [30] while neck injury was associated with cadaver head decelerations of $112 \mathrm{~g}$ [31]. These cadaveric studies, then, suggest varied responses to accelerations as a function of anatomic site and impact characteristics.

Our methods pose limitations on the usefulness of the data. We used experienced skiers who committed contrived falls to standardize the event, reduce variability, increase efficiency in data capture, and maximize participant safety. Nonetheless, these falls represent an artificial event and likely represent only one of an entire spectrum of fall directionalities. As well, experienced skiers may not represent the population at greatest risk for falling. The present study, then, is an attempt to furnish preliminary insights into the impacts arising from water skier falls - it certainly is not a definitive or conclusive effort.

As well, aberrant instrument movement may have contributed to some of the large accelerations seen. Our strategy to secure the accelerometer was one designed to provide instrument rigidity while facilitating relatively quick instrument exchanges between skiers as well as anatomical areas. Finally, high speed video would have provided more exacting analysis of initial contact at the moment of impact. This is especially relevant as the axes of orientation changes with a change in body position, from an upright to a prone posture at impact. Even slight twists or turns of the torso or head change the coordinate axis and make precise analysis impossible without concomitant video data.

\section{CONCLUSION}

We conclude that low-speed skier falls generate subinjurious impacts that are characterized by short-duration, low magnitude accelerations. Additional study of human falls onto water at higher speeds is needed to provide a more comprehensive, broader view of impact accelerations associated with this recreational sports activity. This, in turn, would permit a more realistic assessment of the potential for injury.

\section{ACKNOWLEDGEMENT}

Declared none.

\section{DISCLOSURE / CONFLICT OF INTEREST}

None of the authors received support or benefits from government, industry or private philanthropic organizations. UPMC Hamot provided support to affiliated investigators in the form of wages/salaries.

\section{REFERENCES}

[1] "Recreational Boating Statistics". Available at: http://www.uscgb oating.org/statistics/accident_statistics.aspx [Accessed: March 30, 2012].

[2] Hostetler SG, Hostetler TL, Smith GA, Xiang H. Characteristics of water skiing-related and wakeboarding-related injuries treated in emergency departments in the United States, 2001-2003. Am J Sports Med 2005; 33(7): 1065-70.

[3] McCarthy GF. Hazards of water-skiing. Med J Aust 1969; 1: 481

[4] Ramey RF. Intrarectal tear with bleeding from water-skiing. J Fla Med Assoc 1974; 61: 162.

[5] Gray HH. A risk of waterskiing for women. West J Med 1982; 136(2): 169 .

[6] Lee RY, Miller S, Thorpe C. Intrarectal tear from water skiing. Am J Gastroenterol 1992; 87(5): 662-3.

[7] Gomez GA, Martin LC, CastroMR. Nautical accidents: unique injuries. Surg Clin North Am 1991; 71(2): 419-31.

[8] Banta JV. Epidemiology of waterskiing injuries. West J Med 1979; 130: 493-7.

[9] Grace N. Waterskiing hazards: nature and prevention. J Sports Med 1974; 2(4): 212-6.

[10] Hummel G, Gainor BJ. Waterskiing-related injuries. Am J Sports Med 1982; 10(4): 215-8.

[11] Sallay PI, Friedman RL, Coogan PG, Garrett WE. Hamstring muscle injuries among water skiers. Functional outcome and prevention. Am J Sports Med 1996; 24(2): 130-6.

[12] Stanisavljevic S, Irwin RB, Brown LR. Orthopaedic injuries in water-skiing: etiology and prevention. Orthopedics 1978;1(2): 1259.

[13] Horne J, Cockshott WP, Shannon HS. Spinal column damage from water ski jumping. Skeletal Radiol 1987; 16(8): 612-6.

[14] Mizutani T, Goldberg HI, Parr J, et al. Cerebral dissecting aneurysm and intimal fibroelastic thickening of cerebral arteries. Case report. J Neurosurg 1982; 56(4): 571-6.

[15] Greenberg J, Salinger M, Weschler F, et al. Circumflex coronary artery dissection following water skiing. Chest 1998; 113: 1138-40.

[16] Weissert S, Han J, Shah O. Renal artery pseudoaneurysm presenting 3 years after deceleration injury. Can J Urol 2009; 26(3): 4687-9.

[17] Roberts SNJ, Roberts PME. Tournament water skiing trauma. Br J Sports Med 1996; 30: 90-3.

[18] Zaborowski A. Human tolerance to lateral impact with lap belt only. Society of Automotive Engineers 1964; Document No. 640843, Warrendale, PA.

[19] Cheng R, Mital NK, Levine RS, King AI. Biodynamics of the living human spine during - Gx impact acceleration. Society of Automotive Engineers 1979; Document No. 791027, Warrendale, PA.

[20] Stapp JP. Human exposure to linear decelerative force in the backward and forward facing seated positions. Mil Surg 1951; 109(2): 106-9.

[21] Available at: http://www.mchenrysoftware.com/HIC $\% 20$ and $\% 20$ the \%20ATB.pdf [Accessed: 1/10/11].

[22] Zillmer EA. The neuropsychology of repeated 1- and 3-meter springboard diving among college athletes. Appl Neuropsychol 2003; 10(1): 23-30.

[23] Wagner R. A 30-MPH front/rear crash with human test persons. Society of Automotive Engineers 1979; Document No. 791030, Warrendale, PA.

[24] Hirsch AE. The tolerance of man to impact. Ann N Y Acad Sci 1968; 152(1): 168-71.

[25] Weaver CS, Sloan BK, Brizendine EJ, Bock H. An analysis of maximum vehicle $\mathrm{G}$ forces and brain injury in motorsports crashes. Med Sci Sports Exerc 2006; 38(2): 246-9. 
[26] Panjabi MM, Maak TG, Ivancic PC, Ito S. Dynamic intervertebral foramen narrowing during simulated rear impact. Spine (Phila $\mathrm{Pa}$ 1976) 2006; 13(5): E128-34.

[27] Pearson AM, Ivancic PC, Ito S, Panjabi MM. Facet joint kinematics and injury mechanisms during simulated whiplash. Spine (Phila Pa 1976) 2004; 29(4): 390-7.

[28] Ito S, Ivancic PC, Panjabi MM, Cunningham BW. Soft tissue injury threshold during simulated whiplash: a biomechanical investigation Spine (Phila Pa 1976) 2004; 29(9): 979-87.
[29] Ivancic PC, Ito S, Panjabi MM, et al. Intervertebral neck injury criterion for simulated frontal impacts. Traffic Inj Prev 2005; 6(2): 175-84.

[30] Cheynel N, Serre T, Arnoux PJ, et al. Comparison of the biomechanical behavior of the liver during frontal and lateral deceleration. J Trauma 2009; 67(1): 40-4.

[31] McIntosh AS, Kalleris D, Frechede B. Neck injury tolerance under inertial loads in side impacts. Accid Anal Prev 2007; 39(2): 326-33.

Received: February 24, 2012

Revised: April 20, 2012

Accepted: April 24, 2012

(C) Lyons et al.; Licensee Bentham Open.

This is an open access article licensed under the terms of the Creative Commons Attribution Non-Commercial License (http://creativecommons.org/licenses/by-nc/3.0/) which permits unrestricted, non-commercial use, distribution and reproduction in any medium, provided the work is properly cited. 